\title{
Divórcio e controvérsias referentes à guarda dos filhos: a produção da família como efeitos de redes
}

\section{Divorce and controversies concerning the custody of the children: the production of the family as the effect of networks}

Artigo
Original

\author{
Julio Cesar de Almeida Nobre ${ }^{1}$ \\ Ivanete da Rosa Silva de Oliveira ${ }^{2}$ \\ Andréa Magalhães Naves ${ }^{3}$ \\ Danielle Elizabeth da Silva Diamantino ${ }^{3}$ \\ Etelvina Lana de Oliveira ${ }^{3}$ \\ Felipe Boechat Barbosa ${ }^{3}$
}

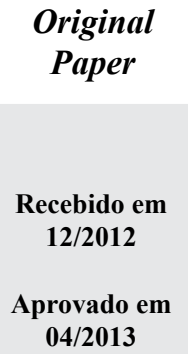

Palavras-chave

Teoria Ator-rede

Família

Guardacompartilhada

\section{Resumo}

Em tempos de intensa instabilidade, entendemos que a Teoria Ator-rede apresenta-se como potente referencial teórico-metodológico para a análise da realidade, pois nos remete a alianças, fluxos e mediações, referindo-se à ação de elementos heterogêneos conectados, caracterizados pela possibilidade do desvio. Nesse caso, a mediação pode ser entendida como um aspecto humano ou não-humano capaz de mobilizar, modificar, potencializar ações dentro de um circuito constituído por uma heterogeneidade de mediadores. Essa perspectiva nos ajuda a entender a realidade a partir da temporalidade das amarrações diversas. É com esse foco que nos voltamos para a produção do artefato família na atualidade. Diferentemente de um processo estabilizado na concepção "pai, mãe e filhos" -naturalizado até meados do séc. XX - estas redes de mediadores que produzem aquilo que entendemos por família até então, parecem instabilizar-se gradativamente. Muitas têm sido as mudanças que acabam por trazer controvérsias para uma circulação estável da família, pois diferentes modos de produção desta colocam em xeque uma natividade possível. Nesse âmbito, um fator de instabilidade, que consideramos por demais pertinente nessa temática, tem sido a prática do divórcio e suas questões acerca da guarda dos filhos. Desse modo, nosso foco de análise no presente trabalho reside na produção da família em uma perspectiva de redes. A pesquisa se propõe a abordar as práticas cotidianas que produzem tal artefato agenciado a um fluxo de heterogêneas e controvertidas mediações em constante movimento - como as questões referentes ao divórcio e à guarda dos filhos. Buscaremos desenvolver uma cartografia descritiva da produção da família na atualidade como efeito de redes, evidenciando suas dinâmicas de conectivas.

\footnotetext{
${ }^{1}$ Graduado em Psicologia, com mestrado e doutorado em Psicossociologia de Comunidades e Ecologia Social, desenvolve pesquisas na área da produção de subjetividade e saberes a partir do referencial da Teoria Ator-rede. 
In an actuality of intense instability, we understand that the Actor-Network Theory is powerful theoretical-methodology for the analysis of reality, because it brings us the alliances, streams and mediations, referring to the action of heterogeneous elements connected, characterized by the possibility of diversion. In this case, mediation can be understood as a human or non-human look capable of mobilising, modify, enhance actions within a circuit comprising a variety of mediator. This perspective helps us to understand reality from the temporality of the moorings. It is with this focus that we turn to the artifact's production family today. Unlike a stabilized in the design process "father, mother and children"naturalized until the middle of the 19th century. XX-these networks seem to unsettle gradually. Many have been changes that ultimately bring disputes to a stable movement of what we mean by family, as different modes of production of the family put in check a Nativity. In this context, a factor of instability, that we consider relevant in this topic too, it has been the practice of divorce and your questions about child custody. Thereby, our focus of analysis in this work lies in the production of family in a network perspective. The research aims to address the daily practices that produce such artifact touted a heterogeneous workflow and controversial mediations in constant motion - as issues relating to divorce and child custody. We will develop a descriptive mapping of family production today as effect of networks, evidencing their dynamics of connectives.

Actor-Network

Theory

Family

Joint-custody

\section{Introdução}

Ao voltarmos nosso olhar para a atualidade, observamos um intenso fluxo interfronteiras que nos instiga a pensar a partir de uma ênfase na mediação, nos fluxos produtores de existência (Bruno Latour, 1994). Com essa atitude, nosso foco de questionamento reside na produção da família em uma perspectiva de redes. A pesquisa se propõe a abordar as práticas cotidianas que produzem tal artefato agenciado a um circuito de mediações heterogêneas em constante movimento. Entendemos tal questão como pertinente na medida em que intensas controvérsias acerca do divórcio e da guarda dos filhos parecem instabilizar as fronteiras daquilo que temos concebido por família. Diversas controvérsias vêm entrelaçando diferentes mediadores que, no mesmo ritmo de suas ações, fazem circular e trazem existência ao artefato família na atualidade. Faz-se importante salientar que utilizamos o termo artefato aqui para evidenciar o caráter produtivo - arte - simultâneo ao seu aspecto de realidade estabelecida - fato.

Nosso referencial teórico requer uma orientação metodológica que possibilite cartografar redes sociotécnicas no que tange aos seus espaços - principais porta-vozes, mediadores e suas conexões - mas também se inscrever no tempo - fluxos dos deslocamentos.
Buscaremos uma abordagem simétrica referente ao estabelecimento de qualquer polaridade, mantendo nosso foco no processo pelo qual a rede se estende. Rastreando tais conexões, abordaremos o que está sendo mobilizado nesse processo heterogêneo.

Propomo-nos, portanto, traçar um relato cartográfico das mediações que fazem circular e acabam por produzir aquilo que entendemos por família. Trata-se de um trabalho descritivo, cuja principal característica, segundo Latour (2008), é que se deve avançar lentamente. Seguindo de nó em nó. Buscaremos rastrear um circuito de mediadores sem remeter para nenhuma solidez a priori. Não almejamos produzir uma dimensão de família enquanto nova concepção ainda mais profunda que as anteriormente produzidas. Ao objetivarmos a produção de um relato, nosso método um tanto minimalista consistirá em seguir os mediadores e descrever ações.

Assim, elegemos como porta de entrada na heterogênea rede produtora da família, os artigos midiáticos e acadêmicos - bem como material jurídico - referentes às questões relacionadas aos processos da guarda compartilhada. Esperamos, com isso, poder identificar alguns importantes porta-vozes que, na atualidade, falam pela rede e indicam novas pistas a serem seguidas. Antes, porém, abordaremos mais amplamente o referencial teórico que nos orienta nesta empreitada. 


\section{A Perspectiva da Teoria Ator-rede}

Em tempos de intensa instabilidade, entendemos que a Teoria Ator-rede - TAR - apresenta-se como um referencial teórico-metodológico bastante potente para a análise da realidade. Tal teoria nos remete a alianças, fluxos e mediações, referindo-se a elementos heterogêneos conectados, caracterizados pela possibilidade do desvio, sejam eles humanos ou não-humanos. Nesse caso, a mediação pode ser entendida como ação capaz de mobilizar, modificar, potencializar fluxos em um circuito.

Essa perspectiva nos ajuda a entender a realidade a partir de amarrações diversas, um emaranhado de redes que possibilita um dinamismo sempre processual. As conexões, que se articulam e se modificam em processos a envolver humanos e não humanos, apontam para toda uma vida social permeada por constante produção coletiva. Desse modo, toda existência é produto e produtor desses fluxos, delineando novos conceitos, novos fatos, novas produções, constatando que o "foco está na cozinha dos fatos, nas mediações e nas práticas" (LATOUR, 2000, p. 83-84).

Segundo Latour (2000), as controvérsias podem ser entendidas como um importante observatório para o rastreamento de redes, na medida em que é apenas no processo da produção de novas associações que o social pode se fazer, momentaneamente, visível, gerando um rastro das diversas associações entre humanos e não-humanos. Diante de conexões já realizadas, mesmo havendo intenso trabalho para mantê-las existindo, tal trabalho permanece invisível. A caixa-preta representa tais momentos em que a rede se propaga sem maiores controvérsias, estabilizando os fluxos e acabando por cristalizar uma realidade como um fato, no qual humanos e não-humanos (re)produzem as existências de modo tácito. A revelia de tal estabilidade, o fato se movimenta e se modifica intensamente.

No regime de caixa-preta, um fato se produz sem maiores contra-argumentos. Contudo, em algum momento, podem surgir mediações que instabilizam tal circulação. Abertura de caixa-preta é sinônimo de controvérsia e de instabilização da realidade. Nesse momento, um mundo em construção se revela em uma luta coletiva na produção dos fatos. Os teóricos da TAR denominam tais processos como caixa-cinza. Segundo Vinck,
O termo caixa-preta (...) é utilizado na sociologia das ciências para falar de um fato ou de um artefato técnico bem estabelecido. Significa que ele não é mais objeto de controvérsia, de interrogação nem de dúvidas, mas que é tido como um dado (...). Quando uma técnica ainda não está completamente estabelecida como caixa-preta, falamos de caixa-cinza (apud NOBRE; PEDRO, 2007, p. 228).

Esses regimes de caixa-cinza possibilitam o surgimento de novas produções em rede que, ao se propagarem em processos de estabilização, isto é, circularem como bases sucessivas para novas existências, vão se naturalizando. Porém, a revelia de tal naturalização, existe constante tensão. É o que Law (1992) denomina como pontualizações, isto é, um invariável trabalho no sentido de triunfo sobre as resistências. Estamos diante de um campo de lutas entre dispositivos de captura e de resistência em que as práticas voltadas para a produção de espaços acabam por, constantemente, renovar os problemas. Alguma solidez, sempre frágil e fragmentária, se dá, portanto, a partir de intenso trabalho coletivo. Desse modo, quando voltamos nosso olhar para o artefato família, encontramos um efeito de redes, processo coletivo de mediações. Porém, se tal artefato, anteriormente, já circulou sem maiores controvérsias, parece que, na atualidade, isso se altera drasticamente.

\section{O Artefato Família na Atualidade}

O artefato família é algo que podemos considerar como bastante antigo, porém, por outro lado, sua produção parece ter se dado de modos diferenciados, revelando toda uma historicidade articulada a diferentes mediadores. Citando Boarini (2003), a família é uma realidade que se configura como muito velha e muito nova simultaneamente. Quando observamos a necessidade humana de, em tenra idade, devido a sua fragilidade, se cercar de adultos que propiciem sua sobrevivência por meio de cuidados, a família pode ser entendida como um arranjo muito antigo. Porém, a autora salienta que seu caráter de renovação constante, suas múltiplas possibilidades, mantém sempre presente um potencial de novidade. 
A revelia de tal fluidez, a autora argumenta por uma forte tradução da família como

(...) sangue e a habitação em comum

(...) características determinantes da formação da família, cujos membros, via de regra, são constituídos de pai, mãe e filhos. A união entre homem e mulher é selada como eterna ou até a morte, e sua finalidade principal é a reprodução. A manutenção deste grupo é realizada pelo pai, provedor financeiro, e a mãe, provedora dos cuidados domésticos (BOARINI, 2003, p. 1).

Tais redes pareciam fazer circular "família", até meados do século XX, de um modo que entendemos como clássico, isto é, a concepção "pai, mãe e filhos" era estável, não revelando nenhuma controvérsia significativa por muito tempo. Articulados, muitas vezes, com fortes argumentos sociológicos e psicológicos - e mesmos religiosos, biológicos dentre outros - o masculino se produzia como trabalhando fora de casa, gerador de renda para a família enquanto que do feminino, normalmente sem voz ativa, se esperava os cuidados dos filhos e dos afazeres da casa. Os filhos do casal, quando meninos, seriam criados nos moldes do pai - "homem de família" - e as meninas, nos moldes maternos - voltadas "para o lar". Desse modo, podemos observar que o artefato família se produzia fortemente imbricado a um processo educacional cotidiano que fazia circular determinados padrões que articulavam comportamento e sexo dos filhos.

Em sintonia com tais processos cotidianos, as concepções acerca do cuidado infantil no seio familiar, a partir do argumento de Badinter (in ALMEIDA, 2009), têm sido fortemente articuladas à condição da mulher. Desse modo, a maternidade teria acabado por se produzir como naturalmente insubstituível diante dos filhos, e a condição da mulher se traduzido por meio de um instinto de maternagem, uma espécie de amor determinado pelo biológico. O ventre, a gravidez, acabaria por inscrever no corpo feminino tal condição.

Se a mulher se produziu como naturalmente cuidadora da prole, a posição do masculino, segundo Nolasco (2001), teria estado intimamente ligada a caracterizações como virilidade, energia, potência e atividade. Diferentemente da condição da mulher, a masculinidade teria se produzido como não redutível ao sexo biológico. Ao invés de algo inato, mais seria uma conquista, uma vitória perante "situações adversas". Desse modo, a posição masculina parece ter circulado como uma medalha a ser conquistada em uma batalha, conferindo honraria ao seu portador. Ser masculino, nesse caso, seria o mesmo que ser herói.

Quando analisamos o argumento de Nolasco articulado ao processo educacional cotidiano descrito anteriormente, podemos afirmar que ambos parecem bastante sintonizados na tradução de um modelo tradicional de família pautado por uma paternidade simbolizada pelo mito do herói, um ideal de pai provedor que, com esse intuito, enfrenta as dificuldades externas à família.

Do início do século XX para cá, tal modelo clássico de família parece se instabilizar gradativamente. Muitas têm sido as mudanças que, acabam por trazer controvérsias para uma circulação estável daquilo que entendemos por família. Influências no âmbito da tecnologia, de novos estudos a respeito da convivência humana, questionamento acerca de uma melhor forma de educação dos filhos dentre outros, acabam por desnaturalizar fronteiras há muito intactas.

$\mathrm{Na}$ atualidade, diferentes modos de produção daquilo que entendemos por família parecem instabilizar uma natividade possível, parcializando bastante o tradicional "pai, mãe e filhos". Casais homossexuais que adotam crianças, mulheres que engravidam e cuidam de filhos sem terem vínculos matrimoniais ou sequer um companheiro, famílias de pai e mãe mais ausentes nos cuidados infantis, nos quais a criança é confiada a terceiros sem relação consanguínea ou é criada pelos avós. Estamos diante de produções que parecem nos revelar que a concepção estruturada de "pai, mãe e filhos" não é mais um modo de circulação estabilizado e a família não pode mais ser entendida como uma caixa-preta. Novas possibilidades parecem tramar uma desconstrução gradativa da paternidade e da maternidade articulada ao biológico. $\mathrm{Na}$ atualidade, muitos são os modos a produzir família que, se por um lado encontram fortes resistências em sua circulação, por outro vêem uma crescente facilidade em sua aceitação. 
Assim, existem intensos questionamentos a respeito da definição de família. O que é família? Como esta vem se definindo e se caracterizando? A caixa-preta há muito fechada parece abrir-se na atualidade. Nesse sentido, Passos argumenta (2003):

Tratando-se de família, creio que o eixo dos seus universais seria exatamente a interdependência entre os sujeitos, que demanda sempre e inevitavelmente a presença do outro, configurado a partir de três perspectivas: da relação dual, da relação entre parcerias e da relação de cada sujeito com o grupo. (PASSOS, 2003, p. 16)

Nesse argumento, família é traduzida como uma função de questões sociais e não biológicas. Mais ainda:

\begin{abstract}
A formação dos vínculos depende, assim, das correntes psíquicas, instituídas a partir de contratos inconscientes, por meio das quais os sujeitos negociam suas posições e seus espaços no universo de reciprocidade que é a família (PASSOS, 2003, p. 18).
\end{abstract}

Ou seja, a família é, aqui, produzida como relações nas quais, por exemplo, as posições materna e paterna são independentes de sexo e desarticuladas do estatuto biológico.

Se houve um tempo em que não havia maiores questões acerca do marido ser o chefe da família, isso é, ser entendido como o provedor e líder, atualmente, outras realidades parecem se produzir. É algo bastante comum encontrarmos a necessidade da esposa trabalhar e colaborar com a renda da casa - mais ainda, muitas vezes é apenas ela a provedora. Deparamos, circunstancialmente, com práticas invertidas em relação a aquelas que se tinha há 30 ou 40 anos atrás. Famílias em que o homem cuida da casa e a mulher que traz a renda. Mais ainda, a maior participação da mulher no mercado de trabalho e algumas de suas novas traduções como provedora do lar acabam por produzir um aumento da importância de terceiros nos cuidados com a prole - creches, avós, escolas, mídias eletrônicas - e articulá-los a instabilização de um espaço familiar há muito cristalizado.
Diante de tais produções, Wagner (2003, p.27) coloca que

A família passa por um momento de perda de referenciais. Se, por um lado, os modelos recebidos nas gerações anteriores parecem estar obsoletos, por outro, carecemos de novas estratégias e padrões educativos que de certa forma resultem eficazes. E na busca de novas alternativas, muitas vezes encontramos velhos padrões com roupagem nova.

O autor argumenta por uma realidade de carência de fronteiras. Parece que, nos dias atuais, estamos diante de uma realidade sem precedentes. $\mathrm{O}$ artefato família parece se produzir como algo desconhecido. Diversas são as práticas que, de um modo ou de outro, objetivam criar estratégias na tentativa de traduzirem novos contornos e a caixa-preta está radicalmente aberta.

\section{O Divórcio e a Guarda dos Filhos}

Nunca a família foi considerada de maneira tão fluida, com contornos tão indefinidos. Um fator que consideramos bastante pertinente devido sua potência de controvérsia e instabilização em relação ao artefato família seria a prática do divórcio e suas questões acerca da guarda dos filhos.

O divórcio, por muitos traduzido como grande avanço jurídico, foi instituído oficialmente com a emenda constitucional número 9 , de 28 de junho de $\underline{1977}$, regulamentado pela Lei 6515 de dezembro do mesmo ano. Tal lei, em sintonia com Código Civil de 1916, enfoca a responsabilidade civil nos processos de dissolução conjugal. Desse modo, fundamentada em uma teoria da culpabilidade, acabava por produzir culpados e inocentes. Ao inocente caberia a guarda do filho, enquanto que o culpado ficaria com a responsabilidade pelos proventos (MOREIRA, 2010).

Porém, com o passar dos anos, tal quadro parece vir se produzindo de modo diferenciado, articulado com diferentes dispositivos como a Constituição de 1988, que baliza o princípio da igualdade quanto aos gêneros e a queda do princípio da culpabilidade diante 
da separação judicial - no Código Civil brasileiro. No âmbito jurídico, parece que, gradativamente, começa-se a produzir uma atitude diferenciada em relação à família articulada ao modelo tradicional. Diante do divórcio, encontramos um turbilhão de controvérsias que, muitas vezes, traz a criança ou adolescente para o centro de uma disputa judicial. Com a Lei 6.515/77 - Lei do Divórcio - foram ampliadas as possibilidades de regulamentação do regime de guarda de filhos. $\mathrm{O}$ Direito, importante mediador em meio a tais controvérsias, articulado ao melhor interesse do menor, vem apontando para a significativa importância da preservação das crianças envolvidas. Tal dispositivo legal tem possibilitado diferentes formas de proteção voltadas para os interesses dos menores.

Em 2008 entra em vigor a Lei 11.698 de 13 de junho do mesmo ano, depois de intensas controvérsias a envolverem diversos e importantes porta-vozes do tema na época, que normatiza duas possibilidades de guarda: a unilateral e a compartilhada, também chamada de guarda conjunta. Enquanto que a primeira normatiza que o adulto - o genitor ou alguém que o substitua - detentor da guarda do menor é responsável pelas decisões inerentes à criação deste, a segunda indica uma situação jurídica na qual ambos os pais, separados judicialmente, conservam, mutuamente, $o$ direito de guarda e responsabilidade do filho.

Essa lei - que traz um pioneiro amparo jurídico aos pais para a divisão das responsabilidades e despesas diante da criação de seus filhos por meio da guarda compartilhada - passa a ter um potencial de impacto como mediador na produção do artefato família. Todas as decisões cotidianas em relação à prole, nesse modelo de guarda, devem ser tomadas conjuntamente. Além disso, a lei afirma que, em tal modelo, os termos da guarda são estabelecidos pelos envolvidos em comum acordo, sendo da alçada do juiz a fixação desses. Desse modo, vemos uma ação na direção de participação conjunta na criação dos filhos. Quanto à moradia do menor,

(...) a fixação dos períodos de convivência no regime de guarda compartilhada, cabe ao juiz, de ofício ou a requerimento do Ministério Público, basear-se em orientação técnico-profissional ou de equipe interdisciplinar $\left(\S 3^{\circ}\right)$, não se in- ferindo disto que se tenha aqui adotado a regra (...) à guarda alternada. O que se pretende é orientar a regulamentação de momentos em que um e outro dos pais terão o filho consigo, porquanto a um deles se deferirá a responsabilidade pela manutenção do menor em sua residência (NÓBREGA, 2008).

Porém, podemos observar que ainda parece prevalecer a preferência do direito à guarda materna em detrimento do pai - aproximadamente $90 \%$, segundo dados do IBGE de 2010 (REVISTA ÉPOCA, 2011). Articulado a tal argumento, entendemos que a jurisprudência brasileira tem tratado do assunto traduzindo, comumente, que é melhor para a criança permanecer na convivência da mãe.

A revelia de tais dados estatísticos, a paternidade vem sendo intensamente reivindicada, em muitos argumentos e processos de divórcio atuais, como mais atuante no interior da família e nos cuidados com os filhos. Os conflitos parecem trazer potencial de controvérsias para as fronteiras familiares e essas parecem encontrar resistências em sua circulação como caixa-preta. Tais conflitos ocasionam forte impacto no cotidiano, na medida em que, nos últimos trinta anos, houve um aumento de $200 \%$ no número de separações e divórcios no Brasil, segundo dados do IBGE de 2007 (ALMEIDA, 2009). A família brasileira acaba por se instabilizar no mesmo passo em que controvertidos argumentos acerca dos malefícios e benefícios da guarda compartilhada - referentes ao cuidado infantil - passam a circular e alistar novos elementos.

Para que possamos abordar a família como efeito de redes, propomo-nos percorrer circuitos e seguir pistas. Norteados pelos desvios, iremos tecendo uma cartografia em função da ação dos mediadores diversos. Desse modo, nosso referencial teórico-metodológico requer uma orientação voltada, simultaneamente, para os espaços e temporalidades. Focalizaremos os principais porta-vozes e mediadores, bem como suas conexões e fluxos de deslocamento. Nesses fluxos, objetivamos uma descrição bastante plana que aponte para um processo de produção da família por meio de uma cadeia de mediadores - sem apelar para nenhuma solidez exterior, nenhuma dimensão mais verdadeira do que o próprio processo de deslocamento. 
Desse modo, seguindo o argumento de Latour, faz-se necessário

1) Buscar uma porta de entrada - É preciso encontrar uma forma de "entrar na rede (...) e, de algum modo, participar de sua dinâmica. 2) Identificar os porta-vozes - (...) é preciso identificar aqueles que "falam pela rede", e que acabam por sintetizar a expressão de outros actantes (...), não se pode deixar de tentar buscar as 'vozes discordantes' (...). 3) Acessar os dispositivos de inscrição, ou seja, tudo o que possibilite uma exposição visual (...) e que possibilitam 'objetivar a rede'; 4) Mapear as ligações da rede - Trata-se aqui de delinear as relações que se estabelecem entre os diversos atores e nós que compõem a rede. Envolve as múltiplas traduções produzidas pelos atores, ressaltando-se suas articulações, em especial: os efeitos de sinergia ou de cooperação na rede; os efeitos de encadeamento ou de repercussão da rede; as cristalizações ou limitações da rede (PEDRO, 2008, p. 12).

Seguindo tais orientações, elegemos como porta de entrada na heterogênea rede da família, artigos midiáticos e acadêmicos que, articulados a material jurídico - todos referentes às questões relacionadas à guarda compartilhada -, atualizam controvertidas mediações que podem nos ajudar a acompanhar sinuosos circuitos produtores da família na atualidade.

\section{Guarda Compartilhada e a Produção da Família: cartografando controvérsias}

A Lei $n^{\circ} 11.698 / 08$ veio a consagrar, no Código Civil brasileiro, o tão elogiado instituto da guarda compartilhada. Não obstante tal instituto já fosse amplamente aceito pela doutrina e aplicado na prática pela jurisprudência, certo é que o reconhecimento legislativo, como ocorreu, pacificou, em muito, as intensas discussões acerca da existência do mesmo. Como afirma a Ministra Nancy Andrigui:
Os direitos dos pais em relação aos filhos são, na verdade, outorgas legais que têm por objetivo à proteção a criança e ao adolescente, exigir-se consenso para a guarda compartilhada dá foco distorcido à problemática, pois se centra na existência de litígio e se ignora a busca do melhor interesse do menor. $O$ poder familiar deve ser exercido, nos limites de sua possibilidade por ambos os genitores. Infere-se desta premissa a primazia da guarda compartilhada sobre a unilateral (STF, 2011).

Em consonância com a ministra, a Revista IstoÉ de 18/11/2011, traduz a paternidade como um conceito em plena mudança, impulsionada pela nova legislação. Tal mudança parece argumentar por uma alteração na própria conceituação daquilo que entendemos por família como um todo.

A imagem do pai que a cada dois fins de semana pegava os filhos na casa da ex-mulher parece antiquada diante das novas formas que as famílias - e a Justiça - encontraram para estabelecer as regras de convivência entre casais separados. A possibilidade de divisão proporcional de direitos e deveres sempre existiram. Mas os preceitos da guarda compartilhada passaram a ser adotados em larga escala de forma mais frequente a partir de 2008 , quando foi aprovada a lei. Como até então eram as mulheres que, em geral, concentravam a guarda - e as tarefas - o resultado é que o ano passou a ter mais "dias dos pais" (JORDÃO; RUBIN, 2011).

Claudete Canezin, professora de Direito Civil da Universidade Estadual de Londrina e membro do Instituto Brasileiro de Direito de Família, traduz a guarda unilateral como aliada de um modelo familiar prejudicial à realidade dos filhos de pais separados quando afirma que a guarda compartilhada veio para suprir as deficiências inerentes aos modelos tradicionais adotados. 
A guarda compartilhada veio à tona para suprir as deficiências dos outros tipos de guarda, principalmente a unilateral, onde há o tradicional sistema de visitas do pai, e a mãe é quem toma todas as decisões sobre a vida da criança. Tal sistema privilegia a mãe, na esmagadora maioria dos casos, gerando relevantes prejuízos, tanto de ordem emocional quanto social, aos filhos.

Os prejuízos também se refletem no pai, cuja falta de contato mais íntimo com os filhos leva fatalmente a um enfraquecimento dos laços amorosos, tornando-o um mero genitor, privando-o do contato cotidiano das responsabilidades e méritos dos filhos (CANEZIN, 2008).

O jurista Paulo Lôbo, doutor em Direito pela Universidade de São Paulo, articula a guarda compartilhada com uma manutenção da presença dos pais no cotidiano do filho, porém, aponta para a produção de uma mudança na concepção de lar - na medida em que argumenta por uma preservação do sentimento de "casa" por parte do menor. Sua defesa é de que tal sentimento deva se manter tanto na residência do pai quanto na da mãe.

A guarda compartilhada é caracterizada pela manutenção responsável e solidária dos direitos-deveres inerentes ao poder familiar, minimizando-se os efeitos da separação dos pais. Assim, preferencialmente, os pais permanecem com as mesmas divisões de tarefas que mantinham quando conviviam, acompanhando conjuntamente a formação e o desenvolvimento do filho. Nesse sentido, na medida das possibilidades de cada um, devem participar das atividades de estudos, de esporte e de lazer do filho. O ponto mais importante é a convivência compartilhada, pois o filho deve sentir-se 'em casa' tanto na residência de um quanto na do outro. Em algumas experiências bem-sucedidas de guarda compartilhada, mantêm-se quartos e objetos pessoais do filho em ambas as residências, ainda quando seus pais tenham constituído novas famílias. (in ALVES, 2009).
Em sintonia com Lôbo, a advogada e psicóloga Alexandra Ullmann - especialista em Direito de Família - argumenta que

O que é necessário ter em mente é a obrigação constitucional de que pais e mães, sejam de que profissão ou classe social forem, têm de prover o crescimento saudável de seus filhos e das crianças que estão sob sua guarda e responsabilidade. Em uma visão mais ampla do instituto, pode-se dizer que a guarda compartilhada representa na quase totalidade das vezes o princípio constitucional do melhor interesse da criança. Mas ressalte-se que também pode traduzir um princípio de melhor interesse dos genitores, posto que a divisão de responsabilidades retira de um dos genitores o peso absoluto das decisões que devem passar a ser partilhadas entre ambos. (ULLMANN, 2010).

Ullmann argumenta por uma família com funções de cuidados infantis mais divididas e, consequentemente, com genitores beneficiados pela guarda conjunta por meio da divisão do peso das decisões de responsabilidades acerca dos filhos. Tal argumento é amplificado na reportagem de Mariana Raphael, no site Bbel, quando umas das entrevistadas, a advogada Sandra Regina Vilela, afirma que

(...) mãe, pai e filhos saem ganhando com a guarda compartilhada. Para a criança é a única opção de manter um pai e uma mãe presentes. Para o pai, a oportunidade de não se sentir um mero coadjuvante na educação do filho. E para a mãe, a possibilidade de reconstruir sua vida, pois pode contar com o pai para ajudar-nos cuidados e educação da criança, afirma Sandra Vilela. (in RAPHAEL, 2011).

Vemos que, nessa matéria, a advogada traduz sutilmente a mãe como figura comumente detentora da guarda e, consequentemente, seria a figura a ser beneficiada com a ajuda paterna - consequentemente abordando a produção de uma nova paternidade, mais presente em relação aos filhos nos processos de divórcio. A psicóloga 
Leila Brito (2005) acaba por desenvolver argumento bastante aproximado ao abordar o papel da psicologia nos processos de guarda. Brito aponta que tal profissional deve manter o foco no melhor interesse da criança, porém defende que tal interesse consiste em manter o menor sob a guarda de ambos os genitores. Nesse caso, em sintonia com o Lôbo, a psicóloga argumenta por uma articulação da psicologia com a guarda compartilhada, no sentido dessa agir com o objetivo de evitar modelos rígidos de guarda monoparental - na qual um genitor ficaria com a responsabilidade pela criança e o outro com direito de visitas quinzenais. Aponta que aquele que fica destituído da guarda acaba por se entender como demitido da família - desligando-se emocionalmente dos filhos. Brito se agencia com as estatísticas para demonstrar que tal genitor tem sido a figura do pai. Desse modo, a guarda compartilhada - articulada às estatísticas - é trazida a argumentar por uma maior participação da paternidade nas responsabilidades com o cuidado infantil - e a guarda monoparental é traduzida como produtora de uma paternidade ausente. Nesse momento, o arcabouço jurídico mais tradicional é trazido e traduzido como tendo tido uma importante ação na produção de uma diluição da presença paterna.

Ribeiro (2005), em sintonia com Brito, Lôbo dentre outros, faz os processos de divórcio argumentarem por uma produção diferenciada do artefato família ao apontar que os litígios nesse tema devem ser entendidos como pedidos de socorro do ex-casal. Esse estaria delegando ao juiz o poder decisório diante de um relacionamento insatisfatório que acarreta uma impossibilidade de autonomia por parte dos pais para com seus filhos - uma postura de passividade diante de decisões que, para a autora, caberiam a eles. Desse modo, a argumentação segue na direção da importância da devolução de tal autonomia aos pais. Seu texto acaba por fazer o artefato família, no divórcio, ser traduzido como família descasada. A autora desvincula família de casal. Assim, família circula por fronteiras bem mais fluidas, pois não estariam vinculadas a uma relação de casal - mas sim ao pai, mãe e filho.

$\mathrm{Na}$ revista Crescer (2012), da Editora Globo, na matéria intitulada $O$ que é Guarda Compartilhada, a advogada Sandra Vilela e a psicóloga Sylvia Meira, sintonizam com
Ribeiro ao articularem a nova lei com uma associação da família com o entendimento e o amor dos pais. Segundo a advogada "Como é preciso definir quem terá mais tempo com o filho, costumo dizer que hoje a Justiça leva o casal à briga. Com a mudança, a primeira opção será a conciliação" (ROGÈRIO, 2012).

Complementando tal argumento, a psicóloga afirma que

A guarda compartilhada é um objetivo nobre, que todo pai e toda mãe devem perseguir. Porque os filhos, esses, sim, o verdadeiro foco de toda e qualquer decisão do casal, só têm a ganhar. Ela sempre funcionará melhor em famílias que tiveram um vínculo forte antes da separação. Pais participativos no casamento continuarão a sê-lo depois do divórcio. E amor não se estabelece por decreto. Não se obriga ninguém a amar. Mas vale tentar uma aproximação. E vale também facilitar a vida dessas famílias. A aprovação da lei abre um novo caminho. $\mathrm{O}$ do entendimento (ROGÉRIO, 2012).

Podemos encontrar em matéria da Revista Veja de 14/08/2011, o argumento bastante significativo do pai André Luiz Jardim da Matta Machado, apontando para novos contornos familiares no pós-divórcio, que afetam e alteram o seu papel de pai na medida em que a guarda dos filhos foi naturalmente se tornando compartilhada. "Foi aí que começou, para mim, o desafio de não perder a minha estrutura familiar, mesmo não estando casado" (RITTO, 2011). Desde o momento da separação, o ex-casal mantém bom relacionamento, trazendo possibilidades de acordos acerca dos momentos em que os filhos ficariam com cada um. Desse modo, André acabou agindo com seus filhos de modo bastante distinto daquele que tinha por hábito enquanto estava casado - "passei a ir à praia, ao cinema, a passear e até a estudar com eles” (RITTO, 2011). Quanto a sua filha - "ela me disse que as lembranças que tem de mim são depois da separação" (RITTO, 2011).

A Revista IstoÉ de 18/11/11, argumenta por uma forte articulação da Lei no 11.698/08 com a produção da família atual. Para tal, por 
meio das estatísticas, apresenta um aumento no número de guardas compartilhadas no país.

De acordo com o Instituto Brasileiro de Geografia e Estatística (IBGE), apesar de a guarda materna ainda ser maioria (87,6\% em 2009), os divórcios com guarda compartilhada aumentaram de 2,7\% em 2004 para 4,7\% em 2009. Mas um levantamento realizado pela Associação de Pais e Mães Separados (Apase) pode refletir melhor a realidade. Enquanto o IBGE se baseia em registros de cartórios e varas de família, e nem todos os casais se casam ou se divorciam, no papel, a Apase constatou que $15 \%$ das guardas já são conjuntas no Brasil (JORDÃO; RUBIN, 2011).

Podemos encontrar o mesmo sendo amplificado pela revista Época online, de 30/11/11, associado a novos dados.

Embora as mulheres continuem sendo as responsáveis pela guarda dos filhos na maior parte dos divórcios, aumentou na última década a proporção do compartilhamento dessa atribuição. Em 2000, elas respondiam pela guarda em $89,6 \%$ dos casos e em 2010 , por $87,3 \%$, o que corresponde a 117.651 menores. Já a guarda compartilhada entre os cônjuges subiu de 2,7\% para 5,5\% no mesmo período, atingindo 8.702 filhos com menos de 18 anos (ÉPOCA, 2011).

Pode-se observar, por meio desses artigos, que as concepções de cuidado e atenção para com os filhos vêm se tornando mais flexível no Brasil, uma vez que a maior parte da guarda dos filhos tem sido a materna, como mostra as estatísticas (IBGE, 2010). Desse modo, após forte controvérsia diante das questões de guarda compartilhada e da importância da paternidade nos cuidados infantis, tal processo parece começar a caminhar no sentido de alguma estabilidade. Na citação abaixo, o Supremo Tribunal Federal (STF) é trazido a falar em prol da guarda compartilhada pela mídia - mais especificamente pela Revista IstoÉ - e acaba por argumentar a favor de uma reestruturação constante dos genitores no sen- tido de possibilitar aos seus filhos um duplo referencial psicológico.

O Superior Tribunal de Justiça, por decisão em agosto deste ano, considerou que a guarda compartilhada pode ser decretada em juízo, mesmo sem consenso entre os pais. $O$ procedimento foi adotado ao ser analisado o caso de um pai (...) que pedia a guarda exclusiva do filho, sob a alegação de que a mãe queria levá-lo para morar em outra cidade. No texto do processo, a relatora, ministra Nancy Andrighi, afirmou ser "questionável a afirmação de que a litigiosidade entre os pais impede a fixação da guarda compartilhada, pois se ignora toda a estruturação teórica, prática e legal que aponta para a adoção da guarda compartilhada como regra." Também ponderou que "a guarda compartilhada é o ideal a ser buscado no exercício do poder familiar entre pais separados, mesmo que demande deles reestruturações, concessões e adequações diversas para que seus filhos possam usufruir, durante sua formação, o ideal psicológico de duplo referencial" (JORDÃO; RUBIN, 2011).

Muitas têm sido as associações ativistas defensoras do argumento de igualdade parental - entre estas estão a APASE (Associação de Pais e Mães Separados) e Pais por Justiça. Mas, segundo elas, o ambiente ainda é de muita luta. A própria matéria da Revista IstoÉ demonstra a instabilidade da controvertida rede produtora da família ao procurar traduzir alguns magistrados como aliados da guarda unilateral quando, agenciada com um importante porta-voz na área do Direito de Família, argumenta que

(...) muitos juízes ainda optam pela unilateral, na grande maioria entregue à mãe. "A guarda materna ainda está enraizada em nossa sociedade", diz o psicanalista, advogado e presidente do Instituto Brasileiro de Direito de Família [IBDFAM], Rodrigo da Cunha Pereira. Segundo ele, ainda há muito preconceito contra a mulher que abre mão da guarda total ou parcial do filho e contra 
a capacidade de um homem de cuidar bem de uma criança. $\mathrm{E}$ isso reflete nas decisões dos magistrados. "A mulher precisa de ajuda e o homem quer ajudar”, diz (JORDÃO; RUBIN, 2011).

Mesmo alguns argumentos que defendem o princípio da guarda compartilhada apontam para instabilidades e dificuldades em sua implementação. Águida Barbosa, doutora em Direito Civil pela USP e Coordenadora da Comissão de Mediação do Instituto Brasileiro de Direito de Família, indica que

Embora a guarda compartilhada, ou conjunta, desponte como o regime ideal para reger as relações de pais e crianças após a ruptura do casal parental, segundo a doutrina e a experiência advindas do direito comparado, sua organização envolve limitações por pressupor a existência de um mínimo de comunicação qualificada entre os genitores (BARBOSA, 2004).

Se por um lado a guarda compartilhada seria um benefício para a criança, ao fazer com que esta continue tendo um relacionamento íntimo com ambos os genitores, ela necessitaria, para dar certo, de um convívio sadio dos genitores. O conflito é chamado a argumentar contra o compartilhamento da guarda. Encontramos argumento similar na matéria de Gláucia Milício, jornalista da Revista Consultor Jurídico, quando ressalta o testemunho da advogada Márcia Trevisioli, especialista em Direito de Família:

Ela considera impossível que um casal que se separou por dificuldades na convivência possa compartilhar a educação de um filho. A guarda compartilhada seria ideal, desde que a relação dos pais fosse excelente, caso estabelecessem projetos semelhantes. Mas, isso é pura utopia. O que vejo nos tribunais são pais utilizando os filhos para negociar o pagamento dos alimentos e a partilha do patrimônio. Como esperar que pessoas feridas possam compartilhar a guarda de um filho se não souberam compartilhar uma vida em comum? (...) Segundo ela, a instituição da guarda compartilhada trará um desequilíbrio ao bem-estar da criança que não está apta a escolher o caminho mais correto. A advogada explicou que, na maioria das vezes, o resultado é desastroso e causa inúmeros problemas para a formação da personalidade da criança como baixo rendimento escolar, distúrbios de personalidade e de conduta. (MILÍCIO, 2007)

A jurista Laura Affonso da Costa Levy, em sintonia com Barbosa e divergindo dos argumentos anteriores de Lôbo, também aponta para questionamentos acerca da guarda compartilhada.

(...) o menor precisa contar com a estabilidade de um domicílio, um ponto de referência e um centro de apoio para suas atividades no mundo exterior, enfim, de uma continuidade espacial (além da afetiva) e social, onde finque suas raízes físicas e sociais, com o qual ele sinta uma relação de interesse e onde desenvolva uma aprendizagem doméstica, diária, da vida (LEVY, 2012).

A autora sinaliza a necessidade de um vínculo único e estável para a criança. Uma referência mais sólida e menos transitória, não apenas espacial, mas afetiva também.

A tais controvérsias referentes à guarda compartilhada, sucederam-se turbulências jurídicas acerca da Alienação Parental - desembocando na Lei 12.318, de agosto de 2010, que passou a normatizar o respectivo tema, como definido por Viegas e Rabelo (2011). Tal conceito remete ao

(...) termo proposto por Richard Gardner, em 1985, para a situação em que a mãe ou o pai de uma criança a treina para romper os laços afetivos com o outro cônjuge, criando fortes sentimentos de ansiedade e temor em relação ao outro genitor (VIEGAS; RABELO, 2011).

Desse modo, os estudos de Gardner se articulam com a legislação quando se observa a redação do caput do art. $2^{\circ}$ da Lei 12.318 :

Art. 2 Considera-se ato de alienação parental a interferência na formação psi- 
cológica da criança ou do adolescente promovida ou induzida por um dos genitores, pelos avós ou pelos que tenham a criança ou adolescente sob a sua autoridade, guarda ou vigilância para que repudie genitor ou que cause prejuízo ao estabelecimento ou à manutenção de vínculos com este. (BRASIL, 2010)

Por alienante entendeu-se aquele que

(...) busca produzir na criança (alienada), da qual, de ordinário, detém a guarda unilateral, uma falsa situação cuja finalidade é denegrir a imagem do (...) genitor [alienado] e, assim, tipificá-lo como vilão aos olhos da criança/ adolescente (PELEJA JÚNIOR, 2010).

Eduardo Barbosa (2010), Conselheiro da OAB/RS e Diretor da Escola da OAB/ $\mathrm{RS}$, aponta, em matéria publicada na Revista Consultor Jurídico, que

Um dos motivos pelos quais a guarda compartilhada está sendo mais adotada ultimamente é que se evite a Síndrome da Alienação Parental, que acontece quando um dos cônjuges incita o filho a cultivar a repulsa em relação ao outro cônjuge. No caso da guarda compartilhada, ambos os pais estão mais presentes na vida dos filhos, dificultando a prática da síndrome, pois os genitores podem ver os filhos em dias mais frequentes e consecutivos, não sendo escravos do rigor das visitas marcadas mais espaçadamente (BARBOSA, 2010).

Nesse argumento, a guarda compartilhada se agencia com a convivência familiar e com ausência de alienação parental, acabando por se articular com uma tentativa de se evitar que haja uma possível SAP - Síndrome da Alienação Parental - em um argumento no sentido de que os filhos em questão estejam constantemente na presença tanto do pai quanto da mãe. No entanto, como o próprio art. $2^{\circ}$ relata, são várias as pessoas que se vêm envolvidas nessas relações conflituosas - revelando a complexidade da família. Articulados com o argumento do advogado Jesualdo Junior (2010), podemos observar que
(...) o texto poderia sugerir que a alienação parental também se dará quando a criação da dificuldade de convivência e relacionamento tiverem por vítimas alienadas os avós. Sobretudo porque o art. $2^{\circ}$, VII, trata de situação que diz respeito diretamente a eles (ALMEIDA JÚNIOR, 2010).

Ainda neste raciocínio, prossegue o autor,

Cada vez mais a jurisprudência e a doutrina destacam a necessidade dos laços afetivos com os avós, concedendo-lhes, inclusive, direito de visita autônomos e, em alguns casos, a própria guarda. Ora, se têm os ônus das obrigações alimentares, também devem ter os bônus da guarda e do direito de visitas avoengos (ALMEIDA JÚNIOR, 2010).

Muitos são os argumentos que traduzem como comum a decisão judicial da guarda ser destinada com frequência à mãe que, por vezes magoada, se sentindo ferida e abandonada, dá início a uma guerra com o ex-cônjuge ou parceiro, usando o filho como arma. Tais argumentos apresentam como sendo práticas cotidianas as ações visando a denegrir a imagem do pai - traduzido como genitor alienado - diante do filho, por via de comentários maliciosos e, propositalmente maldosos, dificultando de todas as formas o contato paterno com sua prole. São argumentos que articulam as mães, com a questão da guarda de filhos e a família, mas em conjunto com a produção de uma repulsa pelo pai. Conforme argumenta Tamara Brockhausen (2012),

Resiste-se em refletir nas decisões judiciais a nova realidade do pai brasileiro (...). Por exemplo, 'O mito do amor materno' - termos utilizado por Elizabeth Badinter -, que paira em nossa cultura matriarcal (...) pressupõe um valor intrínseco e superior na qualidade da parentalidade das mulheres em relação ao homem (...) que estimulam o abuso do poder familiar, as transgressões e a alocação do filho como objeto de posse (BROCKHAUSEN, 2012, p.15). 
Em matéria do Diário de Cuiabá Online, do dia 02/09/2012, podemos observar um médico veterinário que viveu uma situação grave nesse sentido. No artigo, o presidente do Instituto Brasileiro de Direito de Família nos fornece pistas do quanto a questão da alienação está articulada a uma naturalização da guarda materna: "a guarda materna está enraizada em nossa sociedade”. O Jornal faz a alienação parental argumentar por uma presença mais intensa da figura paterna em relação ao filho e por uma desconstrução da mãe como detentora natural da guarda.

Sem aceitar a separação, diz, a mãe o acusou de abuso sexual contra a filha. Ele chegou a ser preso, passar três dias na cadeia. Depois, durante meses lutou na Justiça para provar que tudo não se passava de uma manipulação, uma invenção criminosa de se conviver com a filha. (...) Essa é a maneira mais cruel, porém mais rápida, de separar pais e filhos, assinala, lembrando que há muitos casos semelhantes ao dele em tramitação na Justiça brasileira (DIÁRIO DE CUIABÁ, 2012).

A Revista VEJA de agosto de 2011, em uma matéria sobre alienação parental, a articula com a produção de um carinho paterno.

(...) os divórcios são uma realidade que as famílias, crescentemente, têm que aprender a lidar. Na opinião do psicanalista e autor do livro "Pai presente", José Inácio Parente, o motivo é simples: "Depois que inventaram o amor, as pessoas se separam mais". As novas formas de união, com os recasamentos e os irmãos de pai ou mãe diferentes deram origem à família moderna. "Mais baseada no afeto do que na consanguinidade", resume Parente. O pai carinhoso é um fator importante nesse processo e é também um atributo para um recasamento, como lembra o psicanalista (RITTO, 2011).

Vemos, portanto, que de constantes reivindicações de uma maior presença paterna na criação dos filhos - muitas vezes articuladas às questões de guarda compartilhada - foram trazidas questões acerca de práticas de alienação de um dos genitores, entendido como alienante - fazendo a família transitar agora por renovados circuitos. A advogada Clarindo (2011), em sintonia com tais argumentos, faz a Constituição de 1988 argumentar contra genitores alienadores ao apontar que a convivência familiar é direito da criança e do adolescente resguardado no art. 227 como prerrogativa fundamental. Aponta que, ao acontecer o divórcio, esse não legitima a separação entre os filhos e os pais, sendo dever daquele que detém a guarda respeitar e fazer valer o direito do outro genitor - que não detém a guarda - conviver com a prole. Porém, seu argumento também pontua que, depois de uma separação conflituosa, é muito comum as mães, quase sempre guardiãs das crianças, criarem empecilhos e - mesmo mediante de artifícios escusos - conseguirem o afastamento do acusado e da suposta vítima.

Sylvia do Amaral (2010), advogada do Direito Civil e Direito da Família e Sucessões, fortalece o argumento de Clarindo quando afirma que

Surge, agora, mais uma tentativa de proteger os pais para que eles possam proteger seus filhos: a possibilidade de lei que criminaliza os pais que promoverem a alienação parental. As alienadoras são as mães, já que na maior parte das vezes é delas a guarda, e parecem não ter consciência de que as vítimas são os filhos. São mães irresponsáveis. Algumas vezes atingem seu intento de forma tão eficaz que os pais simplesmente desistem de lutar por seus filhos (AMARAL, 2010).

Nesse argumento, as mães também são produzidas como grandes responsáveis pela alienação parental, visto que as mesmas acabam por deter a guarda dos filhos na maioria dos casos, diante de pais vitimizados que acabam por desistir da paternidade. Encontramos em Brockhausen (2012) um fortalecimento de tais traduções quando a autora afirma por uma participação do judiciário em tal vitimização.

Como psicóloga jurídica, pude constatar que, diante da demora ou silêncio do Judiciário, alguns pais desistiam

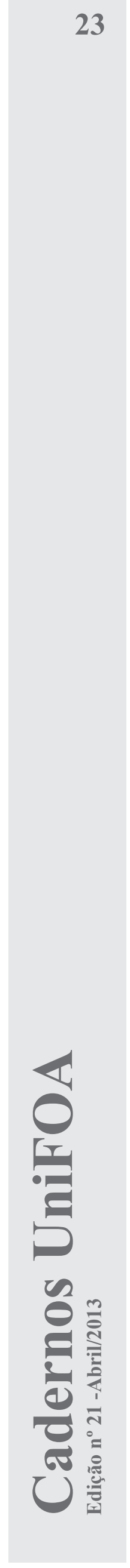


do contato com seus filhos, outros passaram a cometer atos transgressores, ironicamente para manter seu direito de visitas ao filho (ROCKHAUSEN, 2012, p. 16).

Fonseca (2009) ramifica ainda mais a articulação da SAP com mães alienadoras quando, ao apontar que tal patologia afeta mais os meninos, visto que esses são os que mais sofrem com a ausência paterna - em idade entre 8 e 11 anos, pois crianças mais velhas tendem a agir com maior resistência à pressão do genitor alienante. No seu argumento, o menor já segue subentendido como alienado da figura paterna pela mãe.

Porém, embora a SAP se articule fortemente com a ação das mães diante de seus filhos, podemos verificar que não são poucos os argumentos que apresentem casos nos quais o genitor alienante é o pai. A psicóloga do Ministério Público do Estado do Pará, Iracema da Silva apresenta um desses casos:

A esposa tomou a iniciativa da separação pela opção por outro companheiro, saiu de casa, levando consigo os três filhos nas idades de seis e dois anos, e a recém-nascida. Por não ter independência financeira e o genitor se recusar a pagar pensão alimentícia, não conseguiu sustentar a si e aos filhos. Devolveu as crianças ao pai. Durante certo tempo, o pai esperou que a esposa se arrependesse e retornasse ao lar, porém como este fato não ocorreu, ele pediu a separação judicial e a guarda dos filhos. Com o tempo, o genitor passou a informar ao conselho tutelar da área residencial, que a mãe de seus filhos estava convivendo no meio de traficantes e bandidos, razão pela qual ele impedia o acesso dela às crianças, ou permitia na casa dele. Instalada essa situação, a mãe das crianças passou a frequentar a casa do ex-cônjuge para visitar os filhos, segundo ele, somente para infernizá-lo. (...) Após o incidente, o casal voltou a se relacionar pacificamente, o que fez com que o pai pensasse em propor recasamento à mãe de seus filhos, atendendo a sua fé religiosa e ao fato de terem três filhos juntos. A proposta não foi aceita pela ex-esposa, para frustração desse pai, que voltou ao estado anterior de impedimento da visita da mãe aos filhos. As crianças em entrevista mantinham posicionamentos diversos em relação à mãe (SILVA, 2009, p. 80-81).

Podemos observar que muitos são os argumentos, portanto, a traduzirem a Lei 12.318/2010 como um importante aliado de relações familiares mais saudáveis diante dos cuidados infantis. Regina da Silva (2011), por exemplo, doutora em Direito Civil pela USP, ao abordar as consequências da alienação parental em artigo publicado no site Pais por Justiça, articulando tal ato a vários distúrbios psicológicos infantis, comemora o marco de um ano da promulgação da respectiva lei. Seu enfoque é dado às sanções aplicáveis à alienação parental, como estipulação de multa, alteração da guarda e suspensão ou perda do poder familiar. A ministra Andrighi, também é outra defensora da respectiva lei.

(...) os filhos da separação e do divórcio foram, e ainda continuam sendo, no mais das vezes, órfãos de pai ou mãe vivos, onde até mesmo o termo estabelecido para os dias de convívio demonstra o distanciamento sistemático daquele que não detinha, ou detém, a guarda (STF, 2011).

Porém, a respectiva lei ainda encontra dificuldades em seu processo de circulação. Em uma publicação na revista do Conselho Federal de Psicologia, Martins traz vários contra-argumentos em relação à respectiva lei. Primeiramente, a autora articula o próprio conceito de Gardner a imprecisão científica quando, apoiada em estudos anteriores, aponta “(...) que o psiquiatra afirmava a existência da SAP sem apresentar dados de pesquisas que embasassem o conceito criado por ele" (2012, p. 18). Seu argumento também procura vincular Gardner - e a respectiva lei - a uma concepção determinista e avessa a complexidade da questão.

Em sua referência ao litígio conjugal, Gardner engendra, com efeito, uma vi- 
são determinista acerca dos membros do grupo familiar (...) os quais têm ignorada sua singularidade (...). Como comprovam outros estudos, o modo como muitos filhos vivenciam a separação de seus pais é marcado pela diversidade de respostas, não se podendo comparar o comportamento de crianças ao de máquinas que podem ser 'programadas' (MARTINS, 2012, p. 18).

Mais ainda: “(...) estudos chamam a atenção para a complexidade que envolve a questão e não somente para aspectos individuais ou patológicos, como ocorre na teoria do psiquiatra americano" (MARTINS, 2012, p. 18). Desse modo, Martins acaba por questionar, inclusive, o modo como a psicologia se coloca diante da questão, visto que argumenta por uma contestação de conceitos como "programação", entendendo-os como reducionistas.

Em matéria de 08/11/2010 do Portal de Notícias do Senado Federal, podemos acompanhar outro contra-argumento em relação à respectiva lei. Nesse, uma representante do Conselho Federal de Psicologia, Cynthia Ciarallo, traduz família como esvaziando-se de seu poder perante maior intervenção do Estado em seu interior.

"A entrada e a inserção do Estado na instância privada e da família, tema bastante controverso, é um caminho que tem levado a uma retirada da competência e do protagonismo da família nas resoluções dos seus conflitos" (SASSE, 2010).

Por outro lado, a própria psicologia encontra aliados da respectiva lei. Brockhausen (in SASSE, 2010), referência em Psicologia Jurídica e Clínica, contesta o argumento de Ciarallo e aponta que “(...) tem muita lei, mas interfere muito pouco”. Mais ainda

O direito comparado revela-nos que a vida privada da família brasileira sofre pouca intervenção do Estado, deixando assim de regular mais eficazmente diversas situações abusivas (BROCKHAUSEN, 2012, p. 16).
A rede a circular família parece, portanto, ser ainda bastante turbulenta e instável na atualidade.

\section{Considerações Finais}

Podemos observar, a partir de uma cartografia das controvérsias articuladas às questões sobre divórcio, guarda e cuidados infantis, que o artefato família vem sendo trazido a circular por entre mediadores diversos como: juristas, psicólogos, conselhos de classe, cidadãos comuns, mídia, acadêmicos, ONGs etc.

Em meio a tais controvérsias, muitos são os mediadores que traduzem o modelo da guarda compartilhada como a melhor opção para os filhos, sendo essa também uma possibilidade de ambos os pais se manterem como responsáveis pelos cuidados com mesmos. Alguns desses argumentos potencializam a produção de uma paternidade mais articulada aos cuidados com a prole. Por outro lado, essas concepções encontram alguma resistência em sua circulação, na medida em que, além da guarda unilateral se apresentar como opção de alguns magistrados, muitos são os argumentos acerca da dificuldade no estabelecimento do compartilhamento dos cuidados em função de conflitos entre os genitores.

Encontramos ainda, como um importante argumento na respectiva controvérsia, a tradução da família como esvaziada de seu poder diante de uma maior intervenção do Estado - retirando a competência e o protagonismo desta nas resoluções dos seus conflitos. Tal quadro parece ser agravado com questões acerca da SAP.

Enfim, entendemos que o presente relato descritivo da produção da família na atualidade, nos evidencia uma rede de fluxos ainda bastante instável, revelando um caráter de caixa-cinza do respectivo artefato. 


\section{Referências Bibliográficas}

ALMEIDA, L. S. Cuidados infantis: sentidos atribuídos à guarda compartilhada. Rio de Janeiro: UFRJ/EICOS, 2009. Dissertação (Mestrado em Psicossociologia de Comunidades e Ecologia Social). Universidade Federal do Rio de Janeiro.

ALMEIDA JÚNIOR, J. E. Comentários à lei da alienação parental (Lei $\mathrm{n}^{\circ}$ 12.318/2010). Jus Navigandi. 2010. Disponível: $<\underline{\text { http://jus. }}$ com.br/revista/texto/17351> Acesso: 15/9/12.

ALVES, L. B. M. A Guarda Compartilhada e a Lei $\mathrm{n}^{\mathrm{o}}$ 11.698/08. Jus Navigandi. 2009. Disponível: $\quad<$ http://jus.com.br/revista/ texto/12592/a-guarda-compartilhada-e-a-lei-no11-698-08\#ixzz2DFRkEuCP> Acesso: 24/8/12.

AMARAL, S. M. M. Pais responsáveis com seus filhos não podem ser punidos.Revista Consultor Jurídico. 2010. Disponível: < http://www.conjur.com.br/2010-jan-13/ guarda-compartilhada-nao-sendo-aplicadamaneira-deveria> Acesso: 24/8/12.

BARBOSA, Á. A. Análises - Guarda Compartilhada: responsabilidade parental após o divórcio: guarda compartilhada. Pai Legal. 2004. Disponível: < http:/www.pailegal.net/guardacompartilhada/mais-a-fundo/analises/232responsabilidade-parental-apos-o-divorcioguarda-compatilhada $>$ Acesso: 24/8/12 .

BARBOSA, E. Guarda Compartilhada evita manipulação de filhos. Revista Consultor Jurídico. 2010. Disponível: $<$ http://www.conjur.com.br/2010-ago-25/ guarda-compartilhada-filhos-evita-sindromealienacao-parental> Acesso: 24/8/12.

BOARINI, M. L. Psicologia em estudo: refletindo sobre a nova e velha família, vol.8, num.esp.1-2, Maringá: Editora Brasil, 2003.

BRASIL. Lei 12.318/2010. Disponível: $\leq \mathrm{http}$ ://legislacao.planalto.gov.br/legisla/ legislacao.nsf/Viw Identificacao/lei\%20 12.318-2010?OpenDocument $>\quad$ Acesso: $15 / 11 / 12$
BRASIL. Lei 11698. Disponível: < $\underline{\mathrm{http}: / /}$ www.planalto.gov.br/ccivil_03/Ato20072010/2008/Lei/L11698.htm> Acesso: 24/8/12.

BRASIL. Constituição (1988). Constituição da República Federativa do Brasil. Brasília, DF, Senado, 1998.

BRASIL. Lei 6515/77. Disponível: $<\underline{\text { http:// }}$ www.planalto.gov.br/ccivil_03/leis/L6515. htm> Acesso: 24/8/12.

BRITO, L. M. T. Temas de Psicologia Jurídica: de competências e convivências, cantinhos da psicologia junto ao Direito. In BRITO, L. M. T. (org). Temas de Psicologia Jurídica. 3. ed. Rio de Janeiro: Relume Dumará, 2003.

BROCKHAUSEN, T. Alienação parental: caminhos necessários. In Revista Diálogos. N. 8. Brasília: Conselho Federal de Psicologia, 2012. p. 14-17.

CANEZIN, C. C. Da Guarda Compartilhada em oposição à Guarda Unilateral. Site Flávio Tartuci. 2008. Disponível: <http:// www.flaviotartuce.adv.br/artigosc/Claudete_ guarda.doc> Acesso: 13/10/12.

CLARINDO, A. S. As falsas acusações de abuso sexual como instrumento de genitores alienadores. Jus Navegandi. 2011. Disponível: <http://jus.com.br/revista/ texto/18611> Acesso: 13/10/12.

DIÁRIO DE CUIABÁ. Mesmo com decisão favorável, vítima não tem convivência. Diário de Cuiabá. 12 de agosto de 2012. Disponível: $<$ http://www.diariodecuiaba.com.br/detalhe. php?cod=415572> Acesso: 13/11/12.

FIÚZA, C. Direito Civil: curso completo. Belo Horizonte: Del Rey, 1999.

.FONSECA, P. M. P. C. Síndrome de alienação parental. In Revista do Centro de Apoio Operacional Cível / Ministério Público do Estado do Pará. N. 15. 2009. Diponível em <https://www2.mp.pa.gov.br/ sistemas/gcsubsites/upload/25/REVISTA $\% 20$ DO\%20CAO\%20CIVEL\%2015\%285\%29. pdf> Acesso: 15/9/12. 
IBGE. Instituto Brasileiro de Geografia e Estatística. Número de casamentos cai pela primeira vez desde 2002: 2,3\%. 2010. Disponível: <http://www.ibge.gov.br/home/ presidencia/noticias/noticia_visualiza. php?id_noticia=1753> Acesso: 13/10/12.

JORDÃO, C.; RUBIN, D. Unidos na separação. Revista IstoÉ, Comportamento: 18 nov. 2011. Disponível: <http://www. istoe.com.br/reportagens/177923 $\underline{\text { UNIDOS+NA+SEPARACAO }}>$ Acesso: 20/3/12.

LATOUR, B. Reensamblar Lo Social: uma Introdución a la Teoria del Actor-red. Buenos Aires: Manantial, 2008.

Ciência em ação: como seguir cientistas e engenheiros sociedade afora. São Paulo: Editora UNESP, 2000.

Jamais fomos modernos. São Paulo: Editora 34, 1994.

LAW, J. Notes on the Theory of the Actor Network: Ordering, Strategy and Heterogeneity. Centre for Science Studies, Lancaster University, Lancaster LA1 4YN. 1992. Disponível: <http://www.comp.lancs. ac.uk/sociology/papers/Law-Notes- on-ANT. pdf> Acesso: 5/1/06.

LEVY, L. A. C. O estudo sobre a guarda compartilhada. Revista Âmbito Jurídico. Rio Grande. 2012. Disponível: <http://www. ambito-juridico.com.br/site/index.php?n_ link=revista_artigos_leitura\&artigo_id $=6416>$ Acesso: 24/8/12.

MARTINS, A. Síndrome da alienação parental: controle e punição sob o discurso da patologia. In Revista Diálogos. N. 8. Brasília: Conselho Federal de Psicologia, 2012. p. 18-19.

MÍLICIO, G. Guarda compartilhada do filho divide opinião de especialistas. Revista Consultor Jurídico. 2007. Disponível: <http:// www.conjur.com.br/2007-nov-04/guarda_ compartilhada_divide_opiniao_especialistas $>$ Acesso: 24/8/12.
MOREIRA, L. M. R. Aspectos gerais da guarda compartilhada. In Âmbito Jurídico, Rio Grande, XIII, n. 81, out 2010. Disponível $<$ http://www.ambito-juridico.com.br/ site/index.php?n link=revista artigos leitura\&artigo id=8523 $>$ Acesso: 10/11/12.

NOBRE, J. C. A.; PEDRO, R. M. L. R. Redes de Bioética e Biotecnologias da Reprodução: controvérsias teóricas e metodológicas. RECIIS, R. Eletr. vol. 1, n. 2. Rio de janeiro. 2007. Disponível $<$ http://www. reciis.cict.fiocruz.br/index.php/reciis/article/ view/87/85> Acesso: 24/8/12.

NÓBREGA, A. R.. Guarda de filhos: Unilateral e Compartilhada. Inovações da Lei $n^{\circ}$ 11.698/2008. Jus Navigandi. 2008. Disponível <http://jus.com.br/revista/ texto/11494> Acesso: 10/11/12.

NOLASCO, S. De Tarzan a Homer Simpson: banalização e biolência masculina em sociedades contemporâneas ocidentais. Rio de Janeiro: Rocco, 2001.

PASSOS, M. C. A família não é mais aquela: alguns indicadores para pensar suas transformações. In Terezinha Féres-Carneiro (Org.). Família e casal: arranjos e demandas contemporâneas. Rio de Janeiro: EDPUC/ Loyolla, 2003.

PEDRO, R. M. L. R. Redes e Controvérsias: ferramentas para uma cartografia da dinâmica psicossocial. Anais da VII Esocite - Jornadas Latino-Americanas de Estudos Sociais das Ciências e das Tecnologias, Ano 1 - No 2, Rio de Janeiro: 2008.

PELEJA JÚNIOR A. V. Síndrome da alienação parental: aspectos materiais $\mathrm{e}$ processuais. Jus Navigandi. 2010. Disponível $<$ http://jus.com.br/revista/texto/18089> Acesso em 19 de março de 2012.

RAPHAEL, M. Organizar para criar filhos: entenda a guarda compartilhada. 2011. BBEL Estilo de Vida. Disponível < http://bbel. uol.com.br/filhos/post/entenda-a-guardacompartilhada.aspx> Acesso: 19/3/12.

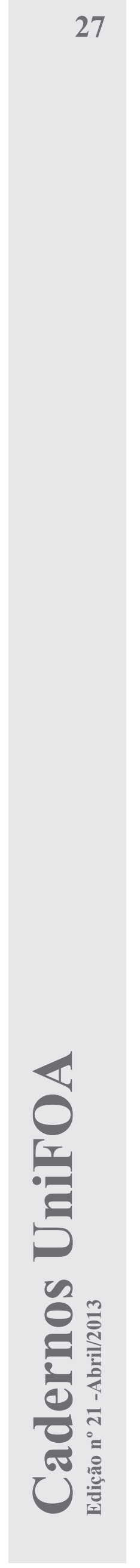


REVISTA ÉPOCA. Taxa de divórcio em 2010 bateu recorde, diz IBGE. Revista Época. 30 nov. 2011. Disponível: < http://revistaepoca. globo.com/Sociedade/noticia/2011/11/taxade-divorcio-em-2010-bateu-recorde-diz-ibge. html> Acesso: 20/3/12.

RIBEIRO, M. L. A psicologia judiciária nos juízos que tratam do Direito de Família no Tribunal de Justiça do Distrito Federal. In BRITO, L. M. T. (org). Temas de Psicologia Jurídica. 3. ed. Rio de Janeiro: Relume Dumará, 2003.

RITTO, C. Pais separados conquistam mais 'dias dos pais' por ano. Revista Veja. 2011. Disponível <http://veja.abril.com.br/noticia/ brasil/pais-separados-conquistam-mais-diasdos-pais-por-ano> Acesso: 20/3/12.

ROGERIO, C. Separação e Famílias Mosaico: o que é guarda compartilhada. Revista Crescer. ed. 228.2012.Disponível<http://revistacrescer.globo. com/Revista/Crescer/0,EMI4461-10520,00. html> Acesso: 20/3/12.

SASSE, C. Lei já contribui para mudar comportamento de pais separados. Jornal do Senado. 08 de novembro de 2010. Portal de Notícias. Disponível <http://www12.senado. gov.br/noticias/materias/2010/11/08/lei-jacontribui-para-mudar-comportamento-depais-separados> Acesso: 20/3/12.

SILVA, I. J. O. A síndrome da alienação parental e o titular do direito de visita. In Revista do Centro de Apoio Operacional Cível / Ministério Público do Estado do Pará. N. 15. 2009. Diponível em <https://www2. mp.pa.gov.br/sistemas/gcsubsites/upload/25/ REVISTA\%20DO\%20CAO\%20CIVEL\%20 15\%285\%29.pdf> Acesso: 15/9/12.
SILVA, R. B. T. Lei de Alienação Parental completa um ano com acertos. Pais por Justiça. São Paulo. 2011. Disponível <www. paisporjusticablogspot.com.br/2011/08/leide-alienacao-parental-completa-um.html> Acesso: 13/10/12.

STF. Guarda compartilhada pode ser decretada mesmo sem consenso entre pais. 2011. Disponível <http://www.stj.gov. br/portal_stj/publicacao/engine.wsp?tmp. area $=398 \&$ tmp.texto=103027 $>$ Acesso: $2 / 9 / 12$.

STF. Alienação parental: judiciário não deve ser a primeira opção, mas a questão já chegou aos tribunais. 2011. Disponível <http://www. stj.jus.br/portal_stj/publicacao/engine.wsp?tmp. area $=398 \&$ tmp.texto $=103980>$ Acesso: 2/9/12.

ULLMANN, A. Guarda compartilhada e poder familiar pelo melhor interesse da criança, com a divisão equânime de obrigações e direitos dos pais. Revista Visão Jurídica. ed. 75. 2010. Disponível <http://revistavisaojuridica. uol.com.br/advogados-leis-jurisprudencia/55/ guarda-compartilhada-e-poder-familiar-pelomelhor-interesse-da-194278-1.asp> Acesso: 13/10/12.

VIEGAS, C. M. .A. R.; RABELO, C. L. .A. A alienação parental. In: Âmbito Jurídico, Rio Grande, XIV, n. 88, maio 2011. Disponível $<$ http://www.ambito-juridico.com. br/site/index.php?n_link=revista_artigos leitura\&artigo_id=9269> Acesso: 26/11/12.

WAGNER, A. A família e a tarefa de educar: algumas reflexões a respeito das famílias tradicionais frente às demandas modernas. In Terezinha Féres-Carneiro (Org.). Família e casal: arranjos e demandas contemporâneas. Rio de Janeiro: EDPUC/Loyolla, 2003.

\section{Endereço para Correspondência:}

Julio Cesar de Almeida Nobre julio.nobre@foa.org.br 